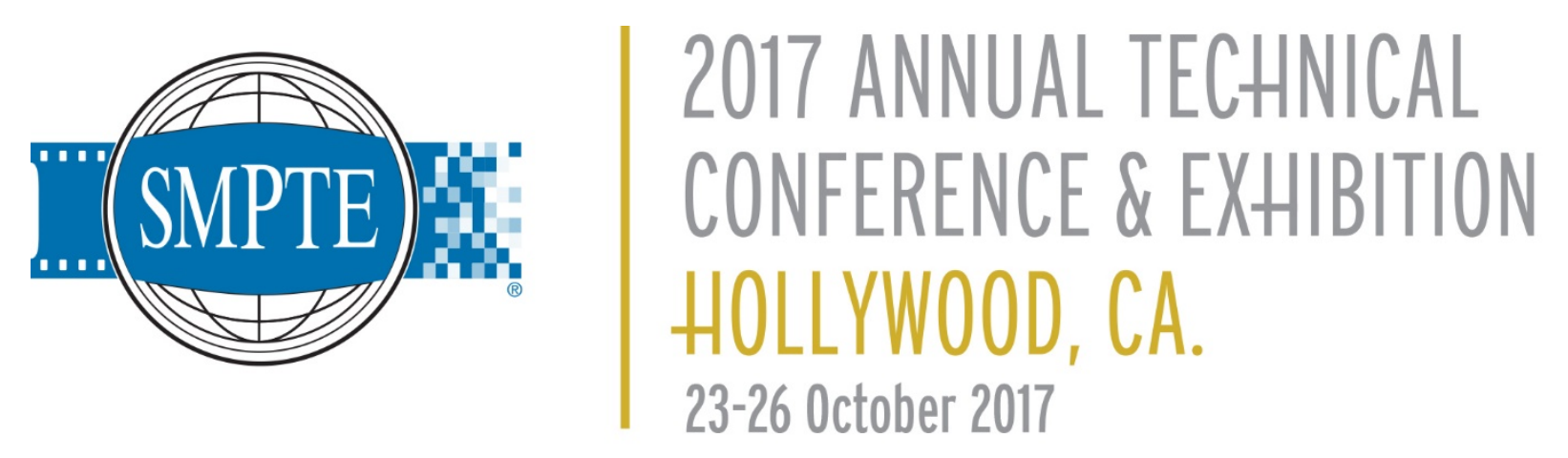

\title{
Engineering a live UHD program from the International Space Station
}

\author{
Rodney Grubbs, NASA MSFC \\ Sandy George, SAIC
}




\section{ANNUAL TECHNICAL CONFERENCE \& EXHIBITION HOLLYWOOD, CA.}

\section{The Challenge}

-What happens when you say "wouldn't it be cool" to Red Digital Cinema's Jarred Land?

- NASA has had a Red Epic Dragon on-board the ISS since 2015

- With the REDCAST module we could use the camera as a source for a live UHD downlink, but...

- We needed an encoder!

- AWS/Elemental built a custom encoder that would accept 4 HD-SDI outputs of 1080P @ 29.97 fps

- All flight hardware arrived at NASA's Johnson Space Center in late October 2016

- Certification

- Launch

- Testing 


\section{ANNUAL TECHNICAL CONFERENCE \& EXHBBITION HOLLYWOOD, CA.}

The Hardware

- New Red Epic Dragon Camera

- REDCAST Module

- Custom Encoder with AWS/Elemental h.265 encoder

- HD-SDI cables and interface dongle for encoder

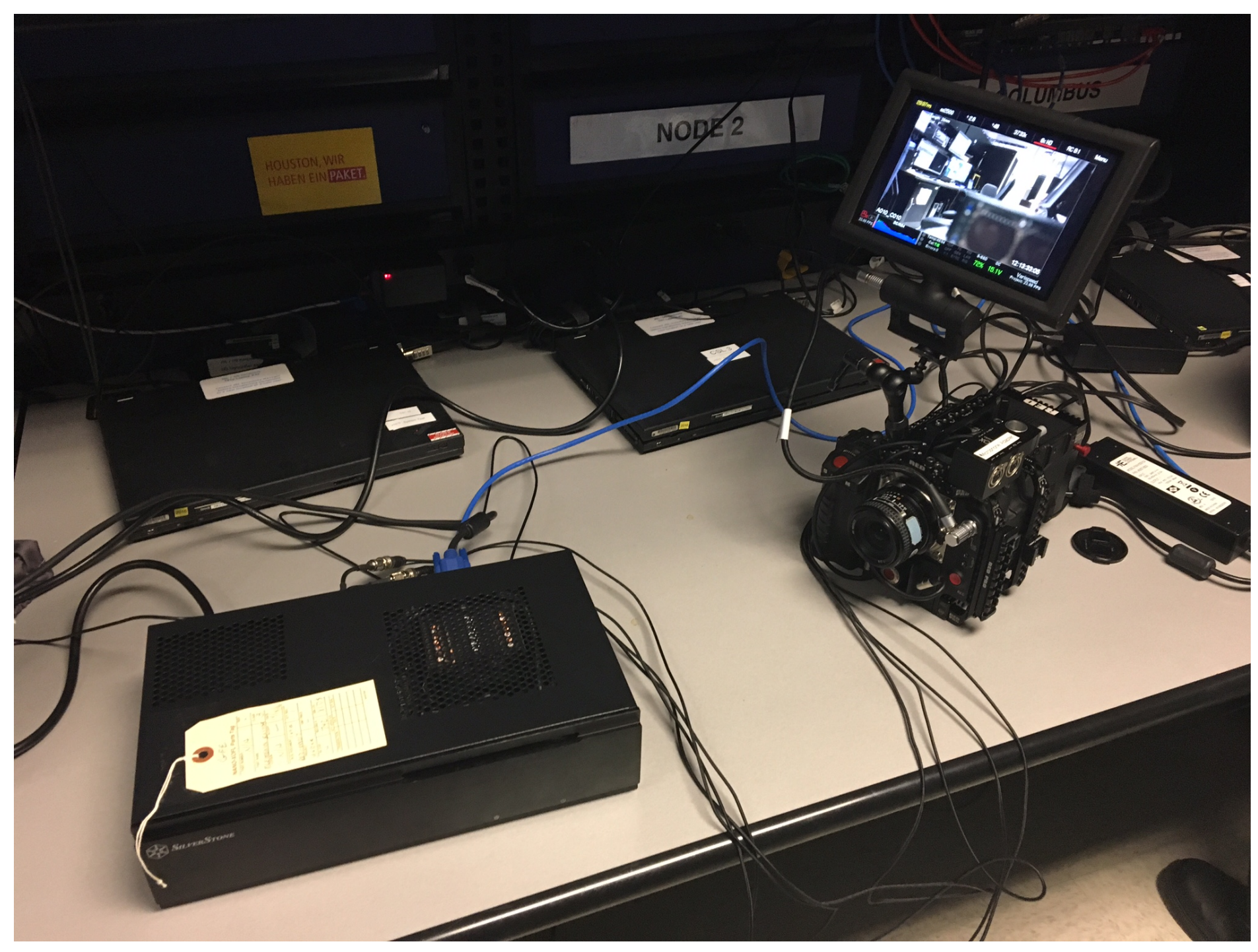




\section{ANNUAL TECHNICAL CONFERENCE \& EXHIBITION HOLLYWOOD, CA.}

\section{System Testing 1/2}

- Red/REDCAST was unable to output embedded sync audio

- Existing HD camera onboard the ISS would provide the audio

- Latency difference of $\sim 4$ seconds

- UHD video would be decoded in order to provide a synchronized UHD h.265 stream
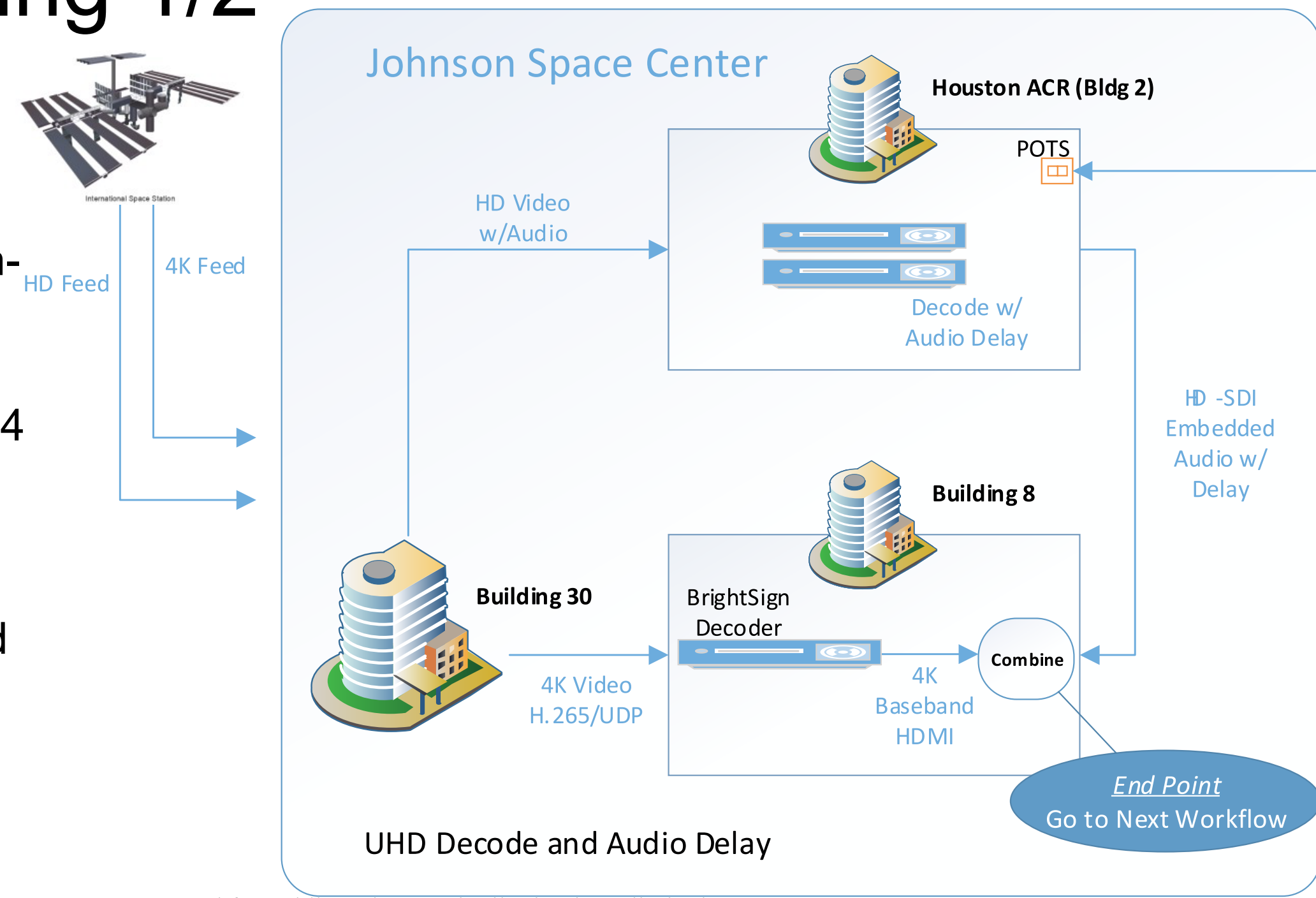


\section{ANNUAL TECHNICAL CONFERENCE \& EXHBBITION HOLLYWOOD, CA.}

\section{System Testing 2/2}

- A series of tests were conducted adding sections of the distribution architecture

- The primary path to the Las Vegas Convention Center utilized the existing NASA TV architecture through our hub@Encompass in Atlanta

- A redundant path utilized a circuit instead of satellite

- Total latency would be 10 seconds!

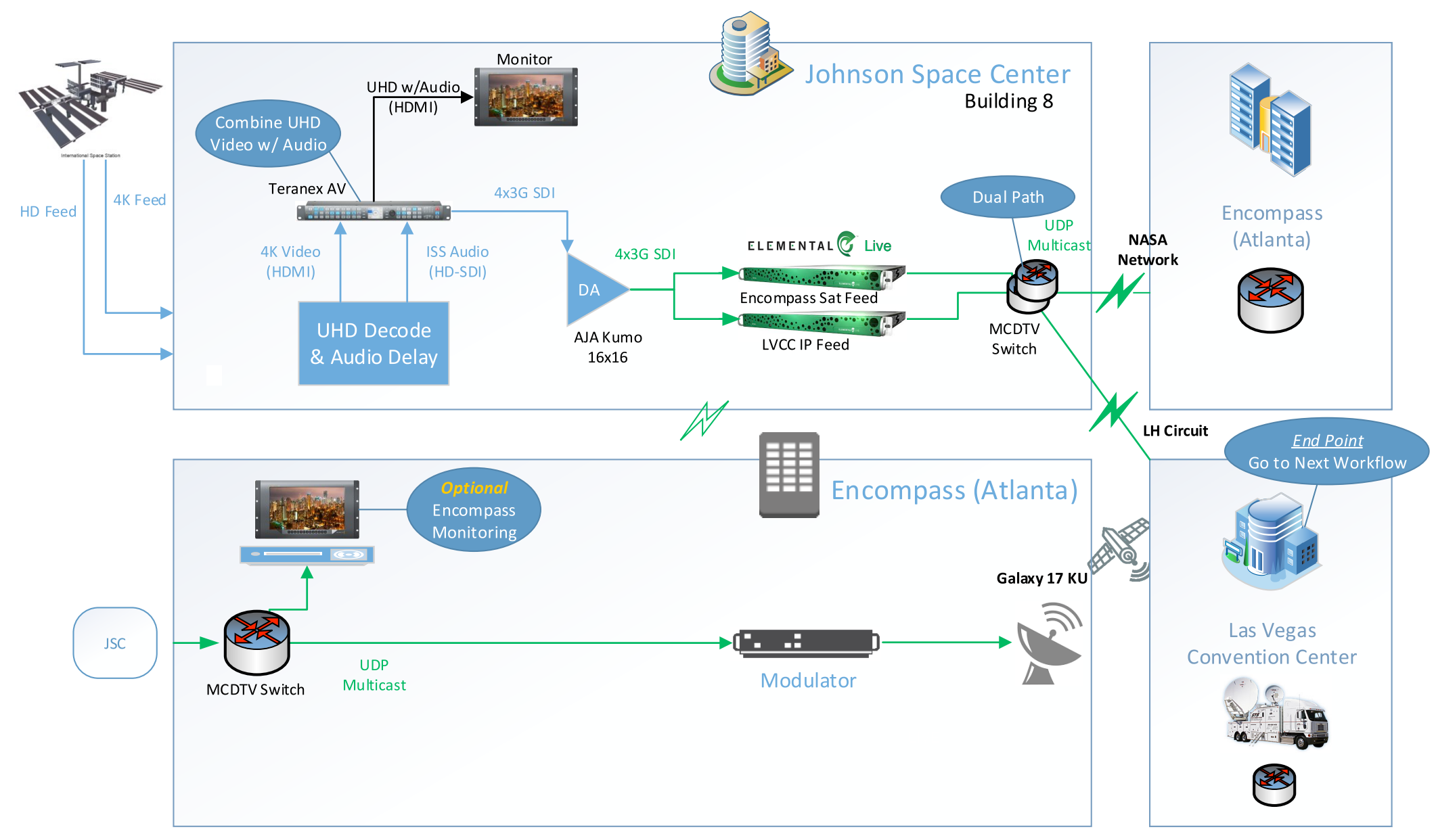




\section{ANNUAL TECHNICAL CONFERENCE \& EXHIBITION HOLLYWOOD, CA.}

\section{The Live Show Architecture}

- AWS/Elemental produced a live UHD show of the entire NAB Super Session including the live ISS downlink

- NASA provided communications for queuing between Mission Control Houston and the ISS

- AWS/Elemental's Sam Blackman handled the latency well

- No technical glitches!

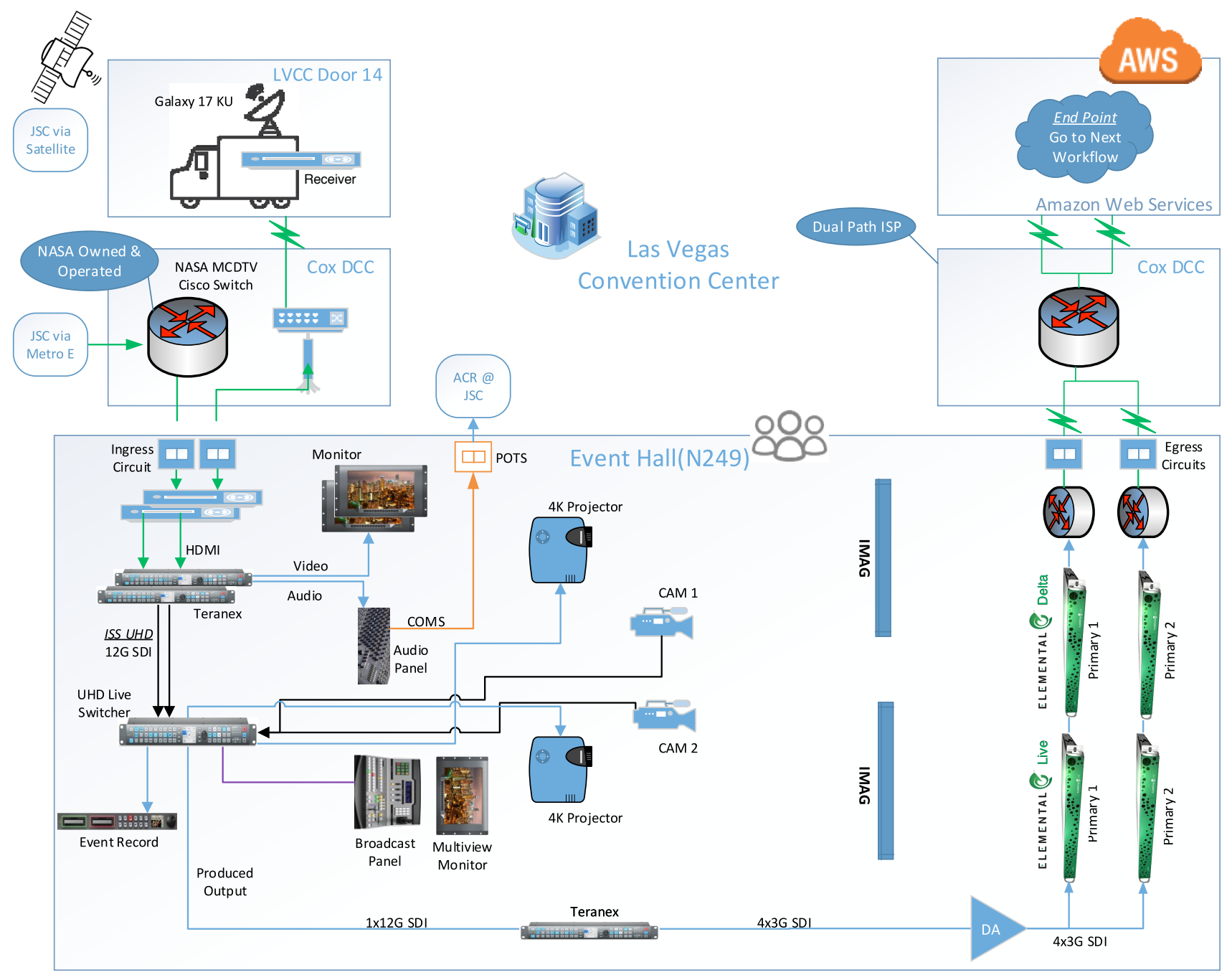




\section{(SUPTE) 2017 ANNUAL TECHNICAL CONFERENCE \& EXHIBITION HOLLYWOOD, CA.}

\section{The Program}
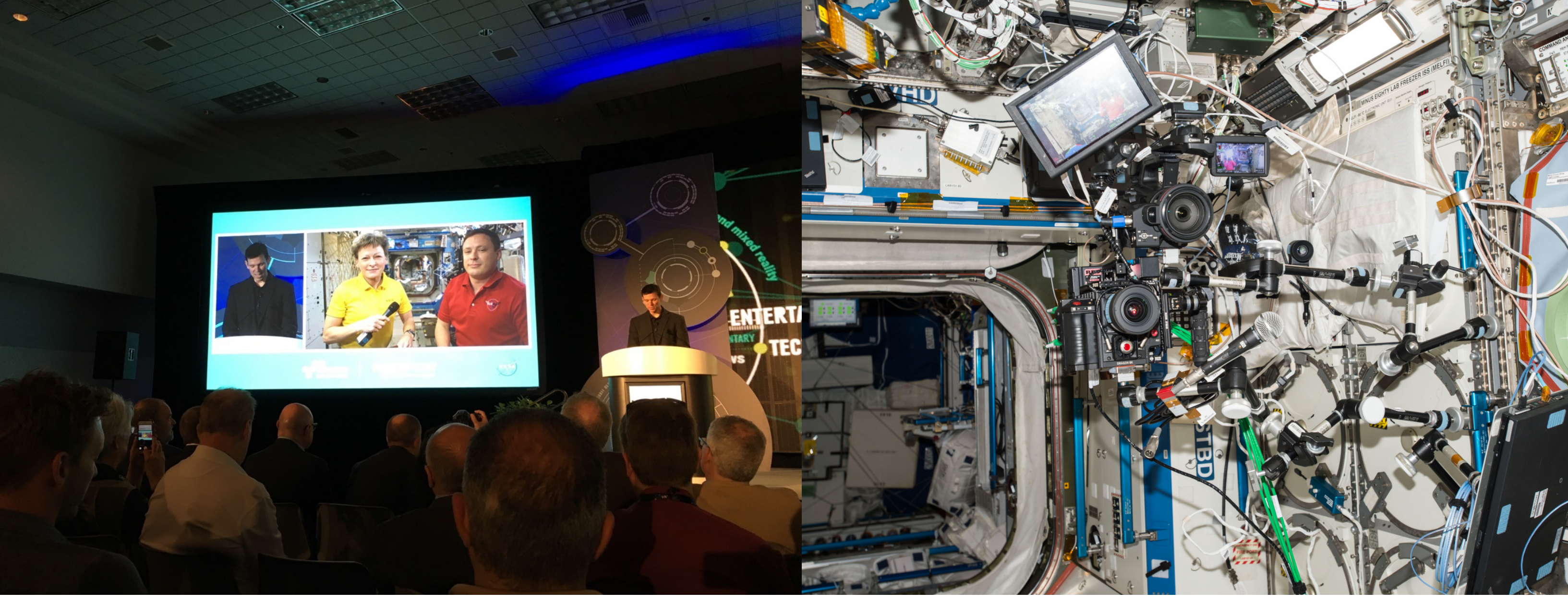
2017 ANNUAL TECHNICAL CONFERENCE \& EXHIBITION HOLLYWOOD, CA.

\section{What's Next?}
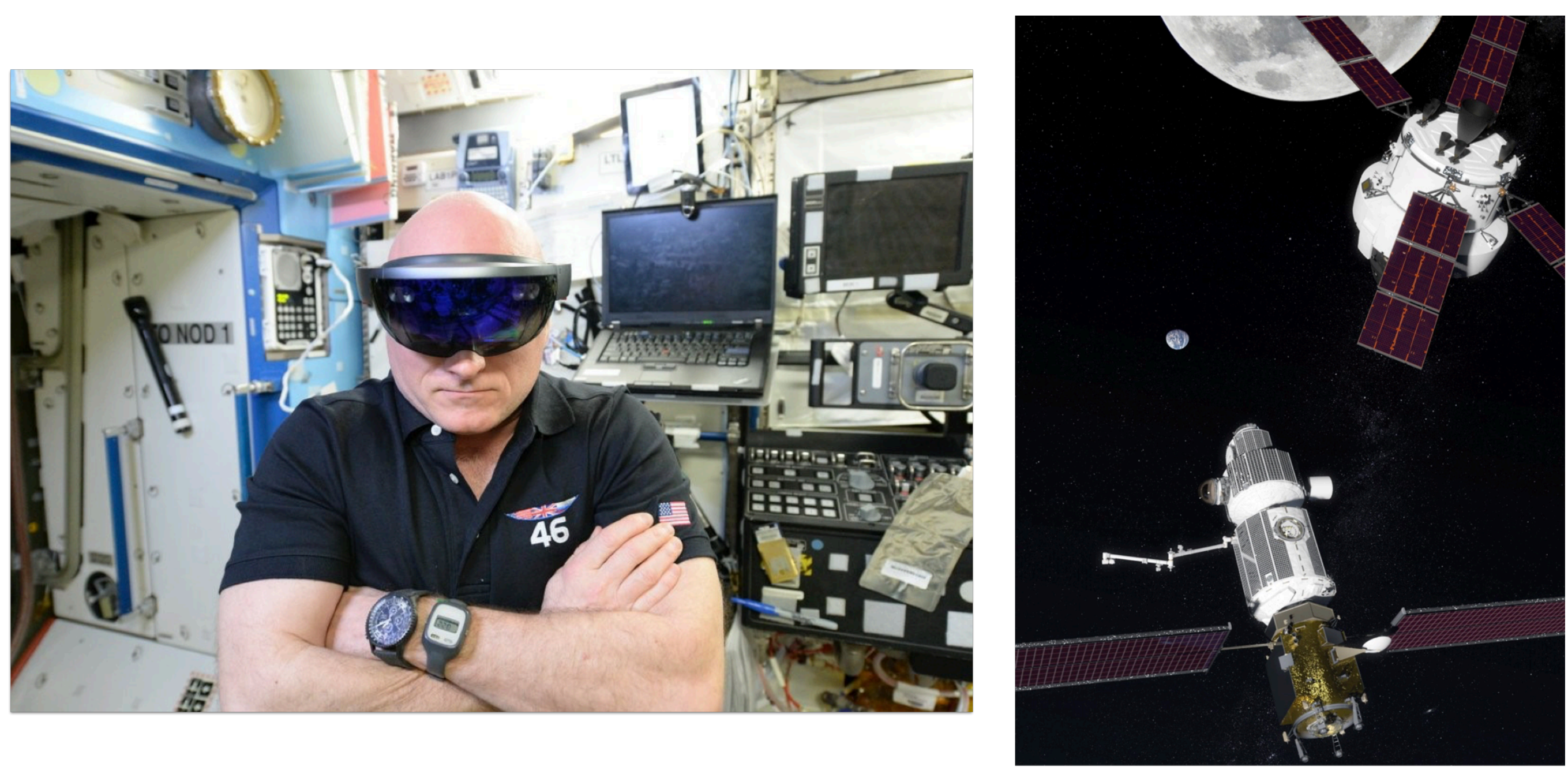